\title{
Load on the air conditioning system in a room with non-round-the-clock working day in the warm season
}

\author{
Elena Malyavina, ${ }^{1, *}$, and Alexander Lomakin ${ }^{1}$ \\ ${ }^{1}$ Moscow State University of Civil Engineering (MGSU) National Research University, Moscow, \\ Russia
}

\begin{abstract}
Calculations of the maximum load on the cooling units of air conditioning systems are important, as they determine the installation capacity of an air conditioner. The load value is influenced by the share of the radiant component in the sum of heat gains coming into a room and making up the load, and the internal thermal stability of the room. Herewith, as the theory of thermal stability states, the higher the internal resistance, the smoother the load peaks, since the heat that comes to an enclosing structure surface is more easily deviated into heavier building materials forming the room interior finishing. In addition, the maximum load on the part-time operating room cooling devices depends on the degree of the room overheating before the beginning of the working day. Moreover, when a room has a minor interior finishing, the heat coming to the inner surfaces of the enclosing structures does not move into the enclosing structure, but raises its temperature. Calculations of the room daily periodic unsteady thermal mode were performed by the method of finite differences in Cartesian coordinates according to an implicit scheme. Provision has been made of calculations of the rooms with different internal heat resistance, the windows of which are facing one of the cardinal directions: South, East, West. The performed calculations have shown the feasibility of heavy finishing for rooms with a high proportion of incoming radiant heat.
\end{abstract}

\section{Introduction}

Calculations of the load on an air conditioning system in the warm season is an important task, since the maximum load determines the installed capacity of the supply air cooling devices in the air conditioner. In turn, the installed capacity affects not only the economic performance of an air conditioning system, but also the quality of specified parameters to be maintained in the room [1-3].

Typically, the designing practice provides determination of the air conditioner refrigeration load by the maximum heat gain in the room during the working day within the design 24 hours $[4,5]$.

\footnotetext{
*Corresponding author: emal@list.ru
} 
However, if the working day does not cover 24 hours in full, and the air conditioner operates only during the working hours or is switched on slightly before, the maximum load can be formed by the accumulated heat coming into the room before the start of the working hours $[6-11]$.

An important role in the formation of the room temperature regime is attached to its ability to maintain a relatively constant temperature with changes in the heat gain, that is, the internal heat stability of the room [12-21]. It manifests itself in two aspects. First, when the heat enters a room before switching on the air conditioner, it accumulates in the room and increases its temperature the more the less the heat resistance of the room [19].

Secondly, when the convective flows assimilate the heat gained in the room by radiant way, the internal heat resistance manifests itself in the fact that the load on the convective cooling system decreases to a greater extent, the higher the heat resistance $[12,13,15,16$, $19,20]$. The transformation of the radiant heat into a convective one is performed by the radiant heat warming up of the building enclosing structure surfaces facing inside. A part of the heat penetrates into the building enclosing structure surfaces, and the air cooling system convective flows, being of a lower temperature, cool them [21].

The purpose of the proposed article is to provide the design estimation of the dependence of the refrigeration load, which assimilates the solar radiation heat gain through the windows of the rooms oriented according to the cardinal directions, and the internal thermal stability of the rooms operating from 9: 00 a.m. to 18: 00 p.m.

\section{The method of the work performance}

A solution shall be found of the problem of a periodic daily non-stationary thermal regime of a room. As the bounding exterior terms, the outdoor air all-day-round temperature fluctuations have been examined according to the Cosine law around the average 24-hour value of $28{ }^{\circ} \mathrm{C}$ with a $7{ }^{\circ} \mathrm{C}$ amplitude (in a mathematical sense, that is the amplitude is the maximum deviation upwards and downwards from the average value).

The calculations have been performed for three ordinary rooms on the intermediate floors of a building having the same geometrical shape: $4,5 \mathrm{~m} \mathrm{x} \mathrm{4,5} \mathrm{m}$ in the plan and 3,5 $\mathrm{m}$ on height with one 2,0 $\mathrm{m} \times 2,0 \mathrm{~m}$ window in the external wall. The total area of the inner surface of the enclosing structures facing the room made $\sum A_{i}=103.5 \mathrm{~m}^{2}$. The rooms had different internal heat resistance mainly due to the different interior room finishing:

- of high thermal stability - the walls and partitions were made of reinforced concrete, the ceiling was a reinforced concrete slab, the floor was a gypsum slab on a reinforced concrete slab;

- of average heat resistance - the cement-sand plaster on the wall and the partitions has been taken into account, the ceiling was a reinforced concrete slab, the floor was covered by linoleum over a reinforced concrete slab;

- of low heat resistance- the perlite plaster on the wall and the partitions has been taken into account, the ceiling was made of the akmigran tiles over a reinforced concrete slab, the floor was covered by a type of a carpet over a reinforced concrete slab.

The windows have been provided with a double glazing in plastic casings; there was a light curtain on the windows from the inside. The windows and the exterior walls have been exposed to total solar radiation, which is typical of the Northern latitude of 56 degrees. The rooms are oriented to one of the cardinal directions: South, East, West.

The room internal heat gain has not been taken into account.

The estimation of the room internal heat stability influence on the formation of the cooling load has been performed by calculation through the method of finite differences in Cartesian coordinates according to the implicit scheme when modeling the daily nonstationary thermal regime of the room. The calculation of the room non-stationary thermal 
regime has been performed in 15 minute time lags. The time varying refrigeration load on the air conditioner has been selected in such a way, that the indoor air temperature during the working hours was within $21.5^{\circ} \mathrm{C}-22.7^{\circ} \mathrm{C}$. The air conditioner was switched on 30 minutes before the beginning of the working day.

Since the numerical method of finite differences does not allow to generalize the thermo-physical characteristics of the rooms in order to assess their internal thermal stability, this study uses the characteristic adopted in the theory of thermal stability $[14,19]$ - the indicator of the room heat absorption. This is all the more legitimate because a periodic problem is under investigation. The rooms of high thermal stability have

$y_{\mathrm{r}}=1939 \mathrm{~W} /{ }^{\circ} \mathrm{C}$, those ones of average thermal stability have $y_{\mathrm{r}}=1137 \mathrm{~W} /{ }^{\circ} \mathrm{C}$, and the rooms of low thermal stability have $V_{\mathrm{r}}=294 \mathrm{~W} /{ }^{\circ} \mathrm{C}$.

In accordance with the theory of thermal stability $[12,13]$ the value of the stabilizing convective flow for smoothing the harmonically changing air temperature in comparison with the disturbing radiant flows will be $a_{\mathrm{g}}$ times smaller. The $a_{g}$ index is called [20] the radiant flow assimilation coefficient. It is equal to

$$
a_{g}=\frac{1}{1+Y_{r} / \sum_{i=1}^{I}\left(\alpha_{c, i} \cdot A_{i}\right)}
$$

where $y_{\mathrm{r}}-$ is the room heat absorption indicator, $\mathrm{W} /{ }^{0} \mathrm{C}$;

$\alpha_{c}$ - the coefficient of convective heat transfer of each surface facing the room;

$i$ - sequence number of the inner surface of the enclosing structure;

$I$ - the number of surfaces of internal enclosing structures facing into the room,

$A_{i}$ - the area of the $i^{\text {th }}$ inner surface of the enclosing structure.

Therefore, when there are mainly radiant heat thermal gains, it is advisable to use a convective system to reduce the energy consumption for lowering the room temperature. As it can be seen from (1), the higher the heat absorption index of the room $y_{\mathrm{r}}$, i.e. the higher the internal heat resistance, the lower the coefficient of radiant heat assimilation $a_{\mathrm{g}}$, which means that it is more profitable to remove the periodic radiant heat load of a room by an air conditioning system.

\section{Calculation results and their analysis}

The result of the calculation consisted in the heat flows, $\mathrm{W}$, of the heat gain in the room due to the heat transfer through the outer wall and window, as well as the solar radiant heat which has been directly penetrating through the window at each time lag. In addition, the calculations have been made of 24-hour changes of the indoor air temperature, radiation and resulting room temperatures, as well as the temperature of the internal surface of all enclosing structures. The amounts of the heat gain and the cold supply have been calculated according to the above data for 24 hours and within the working hours.

The main differences in the calculations for rooms with the same thermal stability may be explained by a different orientation to the cardinal directions. Moreover, the daily solar radiation heat gain is equal in the rooms, which are oriented to the East and to the West. However, the maximum solar radiation heat gain has been stated at 7:30 am in the room oriented to the East, i.e. 1.5 hours before the beginning of the working day, and at 16: 45 p.m. in the room oriented to the West, i.e. during the working hours. As a result, within the 
working hours the amount of the cold supply to the West-oriented room made $30 \%-40 \%$ more than to the East-oriented room.

Figure 1. Illustrates the changes in time of salient heat flows and the Figure 2 - the temperatures during 24 hours.
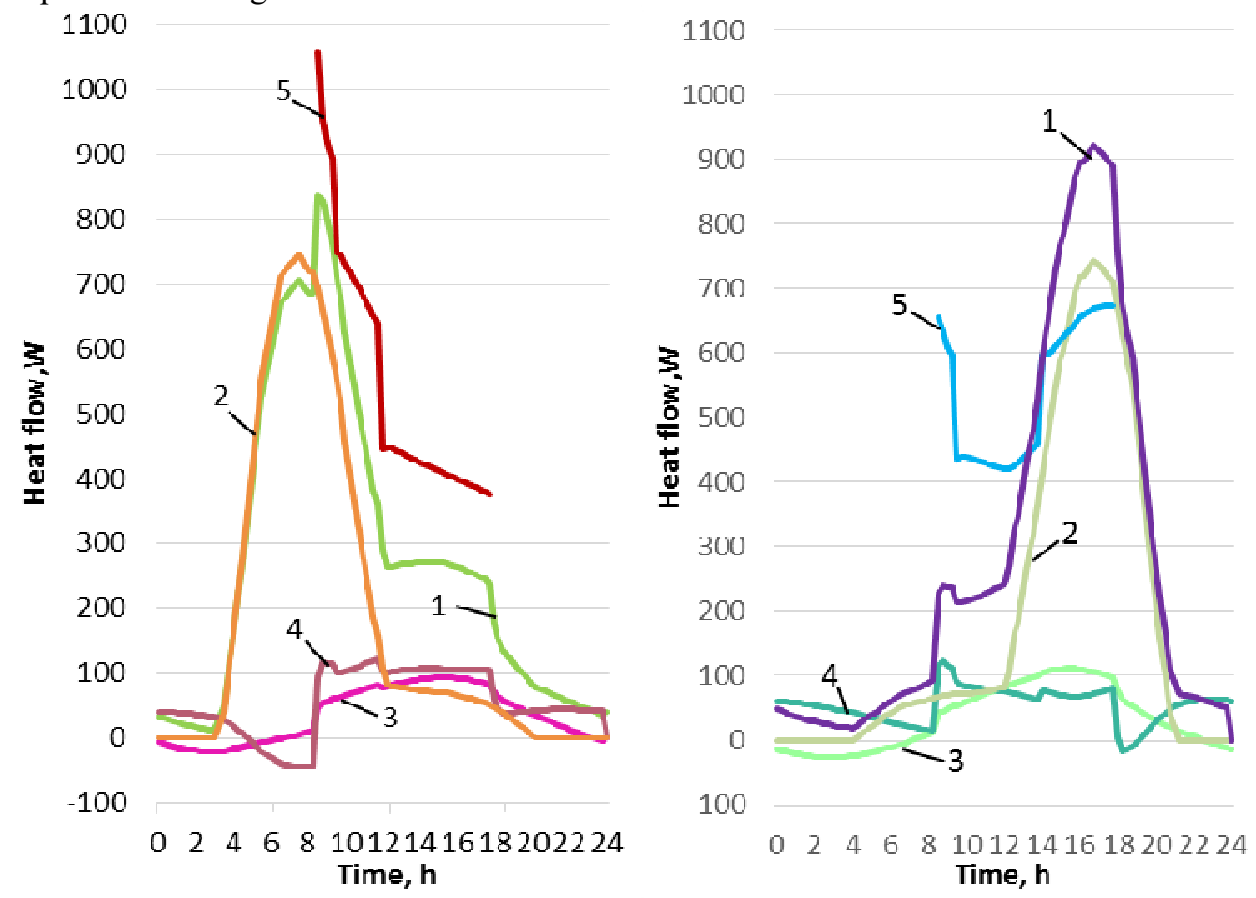

Fig. 1. Daily course of heat flows, $W$, in rooms with low thermal stability a) facing East; b) facing West: 1-total heat gain in the room, 2-heat gain from the solar radiation which penetrates directly into the room through the window, 3-heat gain due to heat transfer through the window, 4-heat gain due to the heat transfer through the external wall, 5-the cold flow, assimilating the room heat excess.

It is clear that the air conditioner load is greater in the East-oriented room in the beginning of the working day, and in the West-oriented one - at the end of the working hours. The figure 2 shows the daily temperature changes of the inner surfaces of the exterior wall and the window.

It can be seen that the wall, having a large thermal inertia, warms up with a greater delay than the window in relation to the maximum intensity of the incident solar radiation. In addition, the figure shows the changes in the indoor air temperature and the resulting room temperature, which is the average between the indoor air temperature and the radiation temperature of the room. Since the radiation temperature is equal to the average temperature of the surfaces facing the room, being formed in particular by heating of the internal surfaces of the enclosing structures due to the solar radiation which penetrates through the window, the room resulting temperature is higher than the air temperature. The difference between the air temperature and the resulting temperature is determined by the presence of the room convective heat gain. Therefore, when the air conditioner works, the air temperature is lower than the resultant one, and out of the working hours, on the contrary, the resultant temperature is higher than the air temperature, since the convective heat comes to the room from the enclosing structures. Since the magnitude of these heat flows is small, the difference in these temperatures is poorly visible. 

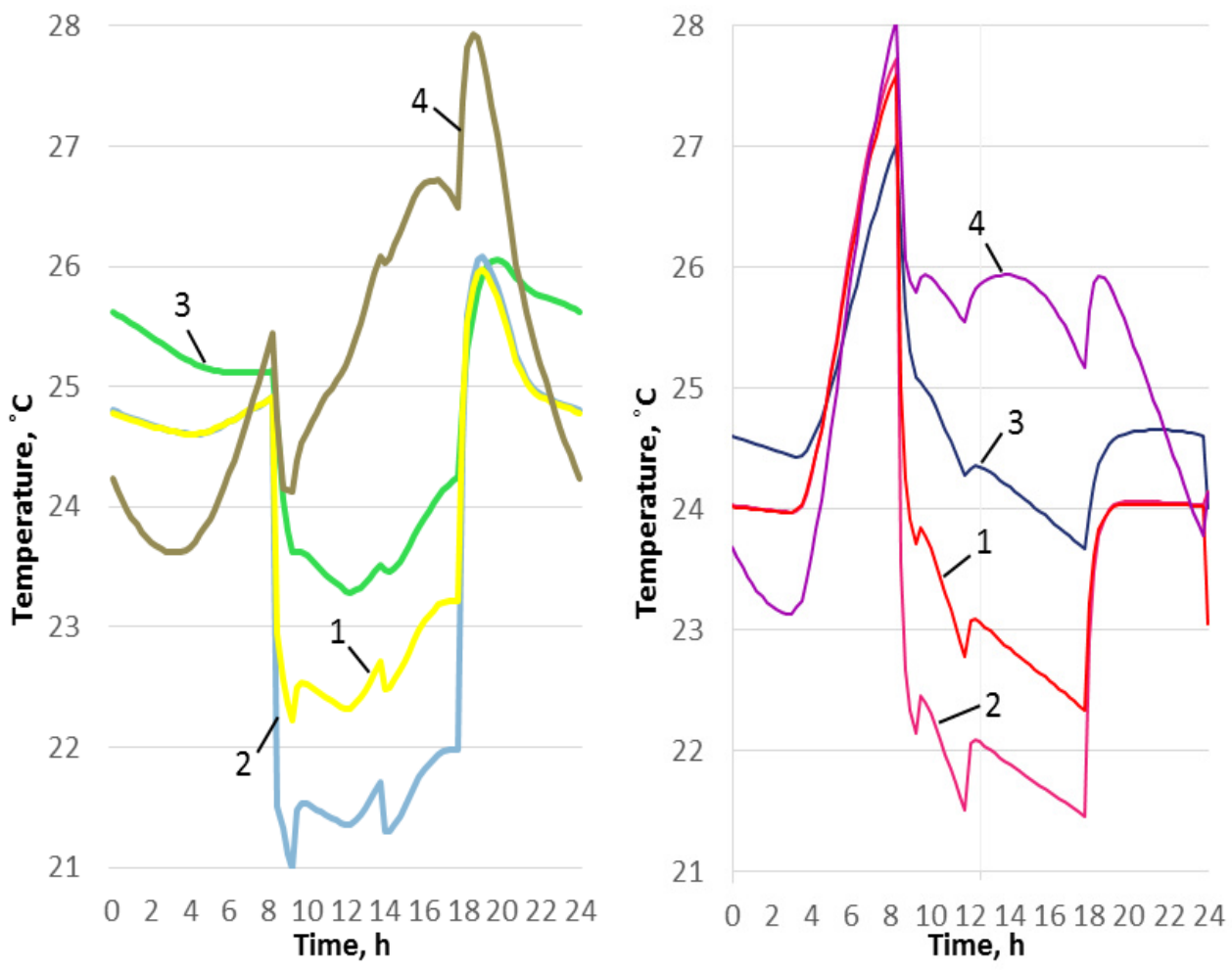

Fig. 2. Daily course of temperatures, ${ }^{\circ} \mathrm{C}$, in the room a) facing East; b) facing West: 1-the resulting room temperature, 2- room air temperature, 3-the temperature of the inner surface of the exterior wall, 4 - the temperature of the inner surface of the window.

Some calculation results are given in the table 1.

Table 1. Daily amounts of heat gains in the room and maximum loads on air conditioner cooling units.

\begin{tabular}{|c|c|c|c|c|c|c|c|c|c|}
\hline \multirow[b]{2}{*}{$\begin{array}{l}\text { Orientatio } \\
\mathrm{n} \text { of the } \\
\text { room to } \\
\text { the } \\
\text { cardinal } \\
\text { directions }\end{array}$} & \multirow[b]{2}{*}{$\begin{array}{l}\text { Internal } \\
\text { thermal } \\
\text { stability } \\
\text { of the } \\
\text { room }\end{array}$} & \multicolumn{5}{|c|}{ Sum of heat gain, W'h } & \multirow[b]{2}{*}{$\begin{array}{c}\text { Sum of } \\
\text { cold } \\
\text { supply, } \\
\text { W.h }\end{array}$} & \multicolumn{2}{|c|}{ Load, W } \\
\hline & & $\begin{array}{l}\text { Total } \\
\text { daily }\end{array}$ & $\begin{array}{c}\text { Daily } \\
\text { throug } \\
\mathrm{h} \text { the } \\
\text { windo } \\
\text { w }\end{array}$ & $\begin{array}{c}\text { Daily } \\
\text { though } \\
\text { the } \\
\text { wall }\end{array}$ & $\begin{array}{c}\text { Daily } \\
\text { of solar } \\
\text { radiatio } \\
\mathrm{n}\end{array}$ & $\begin{array}{c}\text { Workin } \\
\mathrm{g} \\
\text { hours, } \\
\text { total }\end{array}$ & & design & real \\
\hline \multirow{3}{*}{ South } & High & 6463.0 & 1024.7 & 1229.2 & 4209.1 & 5194.1 & 2627.2 & 724.1 & 297.5 \\
\hline & Medium & 6453.8 & 993.4 & 1251.3 & 4209.1 & 5214.8 & 3098.7 & 725.8 & 352.0 \\
\hline & Low & 6339.7 & 863.1 & 1267.5 & 4209.1 & 5260.6 & 4852.6 & 718.2 & 624.5 \\
\hline \multirow{3}{*}{ East } & High & 6843.5 & 1003.7 & 1271.9 & 4567.9 & 3420.3 & 2781.4 & 786.9 & 339.1 \\
\hline & Medium & 6808.9 & 955.1 & 1285.9 & 4567.9 & 3439.2 & 3263.2 & 792.8 & 401.9 \\
\hline & Low & 6712.7 & 842.2 & 1302.6 & 4567.9 & 3702.3 & 5180.4 & 837.0 & 1056.4 \\
\hline \multirow{3}{*}{ West } & High & 6848.9 & 1008.5 & 1272.6 & 4567.9 & 4785.6 & 2755.3 & 919.7 & 331.2 \\
\hline & Medium & 6846.9 & 981.2 & 1297.8 & 4567.9 & 4815.6 & 3272.3 & 921.2 & 372.5 \\
\hline & Low & 6721.8 & 841.6 & 1312.3 & 4567.9 & 4840.6 & 5147.2 & 922.4 & 673.2 \\
\hline
\end{tabular}

The considered calculation options show, that the share of the maximum radiant solar heat load from the total heat gain during the working hours, according to the room 
orientation, makes: to the South-571.2/725.8 $=0.787$; to the East- $695.2 / 837.0=0.830$; to the West-744.5/919.7 $=0.809$. Despite the fact that the orientation to the East makes the biggest share, the required installed capacity of the cooling devices is the largest as well. It happens because just this orientation causes the greatest overheating of the room before switching on the air conditioner. The overheating is manifested not only in the higher temperature of the surfaces facing the room, but also in a much higher temperature of the room air before switching on the air conditioner: the calculations performed in the East-oriented rooms with a minor finishing resulted in the temperature value of $27.7^{\circ} \mathrm{C}$, while those with an orientation to the South and West are $24.9{ }^{\circ} \mathrm{C}$. It is interesting to note, that the overheating of the East-oriented room before the start of the working day plays a greater role in the real load on the cooler than the heat gain in the room facing the West, with an almost simultaneous maximum outdoor air temperature and the intensity of solar radiation within the working hours. The lower load in the West-oriented room explained by the fact that it has been taken immediately after its formation, but the lowering of the maximum cooling device power is achieved by the need to assimilate a larger amount of heat gains per working day than in the East-oriented room.

The higher air temperature before switching on the air conditioner leads to a higher load on the cooling devices of the air conditioner due to the convective component, which is completely assimilated by the convective air conditioning system. Thus, the displacement of the load towards the pre-overheat removal leads to an increase in the proportion of convective heat, which increases the load.

The comparison of design and actual cooling capacity (load) of an air conditioner shows that only at a very slight room finishing the required (real) power of the air conditioner is near or even beyond the design capacity. The design capacity is forecast at the level of the maximum sum of loads from all sources: the heat transfer through the window and the wall, as well as the direct penetration of radiant solar heat through a window with a light curtain. This result of the load formation for a room with a slight finishing indicates the prevailing influence of the overheating before switching on the air conditioner over the transformation of radiant heat flows from solar radiation to convective ones. The slight finishing prevents the heat penetration from the sun-heated inner surface deep into the enclosing structures, which, according to the formula (1), is the reason for nearly absolutely absent load reduction during the transformation of heat flows.

The comparison of the design and the real load of the rooms with medium and high thermal stability acknowledges an important impact of the internal thermal stability of the room to reduction of the real cooling load, which is not taken into account during designing.

The comparison of the cold consumption during the air conditioner operation, shown in the figure 3, also confirms the inexpediency of slight interior room finishing, where the main part of heat consists of the radiant heat at its assimilation by the convective air conditioning system. In rooms with a slight finishing, the cold consumption is close and even higher than the sum of heat gains within the working day in the room. This is due to the same inability of the enclosing structures in such rooms to divert heat deep into the enclosing structures and the need to counter the heat that has warmed up the inner surfaces of the enclosing structures before the beginning of the working day. 

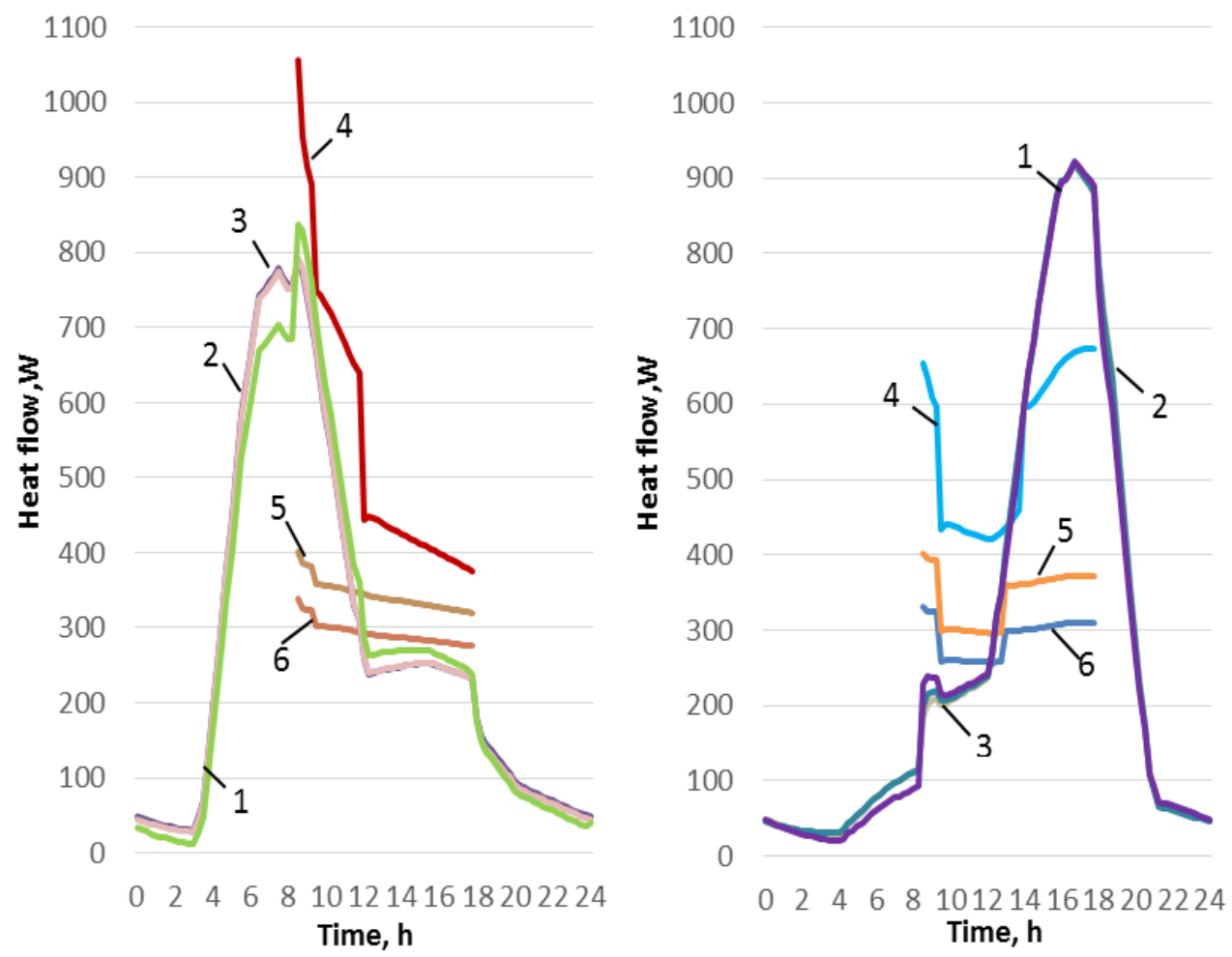

Fig. 3. Comparison of diurnal variations in rooms with different heat stability a) facing East; b) facing West: 1, 2, 3 - total heat gains in the room, 4, 5,6 - streams of cold, assimilating the heat excess in the rooms 1, 4-with low thermal stability, 2, 5- with medium thermal stability, 3, 6- with high thermal stability.

The figure 4 shows the changes in the resulting temperature during the working hours in the rooms with different internal thermal stability. It is shown that the fluctuations of the resulting temperature in rooms with high thermal stability are much smaller than in the rooms with the low one. The maximum time of the resulting room temperature is observed after the hours of the maximum radiant heat flux. Changes in the heat load on the air conditioning system follow the changes in the heat inflows. For an East-oriented room the load assimilating these heat gains is the greatest in the morning, and in a West-oriented room - in the afternoon.

It should be borne in mind that the load on the cooling devices of the air conditioning unit is mainly made of the required need in cold to provide the outdoor air cooling cool up to the indoor air temperature. The calculations considered direct-flow air conditioning systems, which assimilate all heat excesses, without recirculation of the indoor air. The flow rate of the outdoor air to be cooled in the given example has been determined according to assimilation of the heat gain incoming the room, so the sum of the cold flow rate for the outdoor air cooling is not the same, as can be seen from the data in Table 2. It follows from the Table that at the same room orientation the summed cold supply within the working hours increases in the premises when their inner thermal stability decreases.

In the rooms served by air conditioning systems with indoor air recirculation or the indoor air cooling recirculation devices, the outdoor air consumption has been determined by the minimal norm. That is, in all rooms, the outdoor air consumption is the same. The amount of the cold supply to cool the outdoor air to the room temperature will still be different due to the different required inflow temperature. 
As for the inflow temperature, it takes its lowest value at the beginning of the air conditioner operation to remove the room overheating. By the end of the day the inflow temperature is higher in the East-oriented room than in the West-oriented one.

28

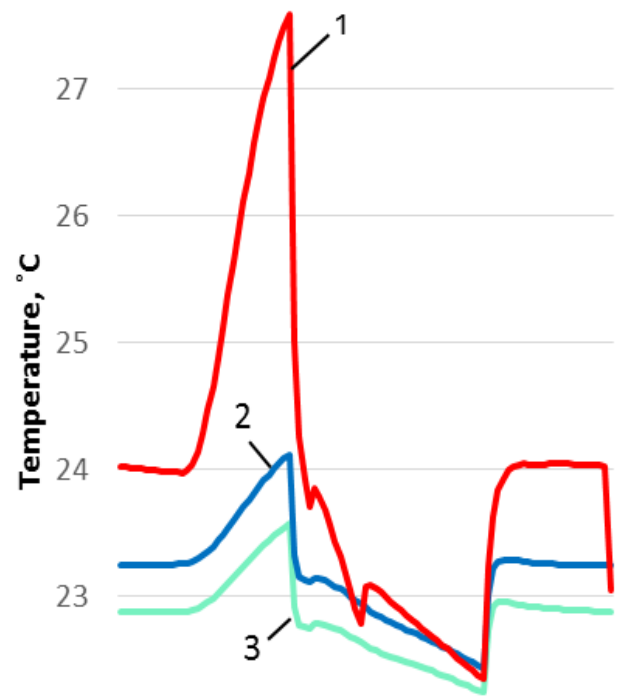

22

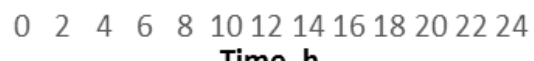
Time, $\mathbf{h}$

28

$$
27
$$

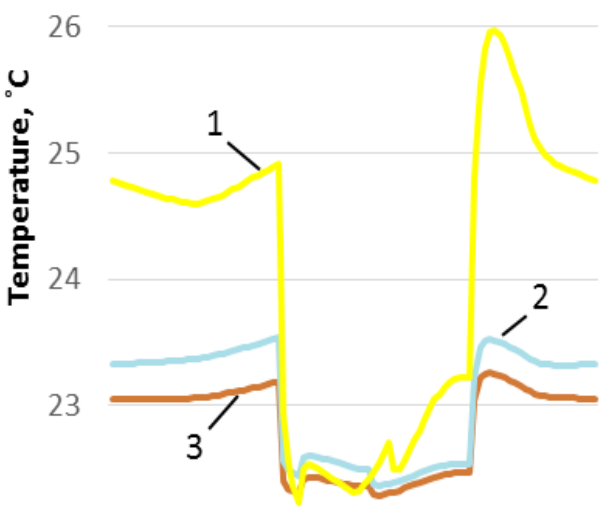

22

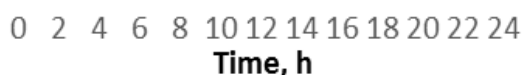

Fig. 4. Comparison of diurnal variations of the resulting temperatures, ${ }^{\circ} \mathrm{C}$, in the rooms with different heat stability a) facing East; b) facing West: 1 - with low thermal stability, 2 - with medium thermal stability, 3 - with high thermal stability.

Table 2. The Sum of loads on the air conditioner cooling units during its operation per 24-hour day for cooling of the outdoor air.

\begin{tabular}{|c|c|c|c|}
\hline $\begin{array}{c}\text { Orientation of the } \\
\text { room to the } \\
\text { cardinal } \\
\text { directions }\end{array}$ & $\begin{array}{c}\text { Internal thermal } \\
\text { stability of the } \\
\text { room }\end{array}$ & $\begin{array}{c}\text { Total sum of cold } \\
\text { supply, } \\
\text { W.h }\end{array}$ & $\begin{array}{c}\text { Sum of cold supply for cooling up to } \\
\text { the indoor air temperature, } \\
\text { Whh }\end{array}$ \\
\hline \multirow{4}{*}{ South } & High & 7607.0 & 4850.9 \\
\cline { 2 - 4 } & Medium & 8856.7 & 5603.4 \\
\hline \multirow{4}{*}{ East } & Low & 13987.7 & 8917.2 \\
\cline { 2 - 4 } & High & 7878.6 & 5097.3 \\
\cline { 2 - 4 } & Medium & 8965.3 & 5702.2 \\
\hline \multirow{3}{*}{ West } & Low & 16979.1 & 11798.7 \\
\cline { 2 - 4 } & Medium & 8353.3 & 5557.2 \\
\cline { 2 - 4 } & Low & 10037.9 & 6724.9 \\
\hline
\end{tabular}

\section{Conclusions}

1. When a room has a slight finishing, the share of the radiant heat gain equal to 0.787 and more, as well as the average area heat absorption indicator of the room enclosing structure interior surface about $Y_{\mathrm{r}} / \sum A_{i}=294 / 103.5=2.84 \mathrm{~W} /\left({ }^{\circ} \mathrm{C} \cdot \mathrm{m}^{2}\right)$ and less, the required 
maximum load on the air conditioner cooling units is close to the design estimates or even slightly exceeds them.

2. For the rooms with internal heat resistance of $y_{\mathrm{r}} / \sum A_{i}=1137 / 103.5=11.0 \mathrm{~W} /\left({ }^{\circ} \mathrm{C} \cdot \mathrm{m}^{2}\right)$ and above the required maximum load on the air conditioner cooling units is below the design values. At this thermal stability of the South-oriented rooms the share of the real load from the design one makes 0.48 , of the East-oriented rooms -0.51 , of the Westoriented rooms - 0.4. At a high internal thermal resistance of $Y_{\mathrm{r}} / \sum A_{i}=1939 / 103.5=18.7$ $\mathrm{W} /\left({ }^{\circ} \mathrm{C}^{2}\right)$ this proportion is equal to: for South-oriented rooms -0.41 , for East- oriented rooms -0.43 , for West-oriented rooms -0.36 .

3. In practice, the proportion of radiant heat coming into the room is lower than the design one, however, the performed calculation study shows the feasibility of major finishing in the rooms with predominantly radiant heat gains where the cooling is required.

4. An important aspect of the result was that the high internal thermal stability leads to a greater reduction in the load on the room cooling devices both during the radiant heat assimilation during the working hours and the formation of the load due to the convective component of the heat accumulated before the beginning of the working day.

\section{References}

1. B. Slee, T. Parkinson, R. Hyde, Can You Have Too Much Thermal Mass? Cutt. Edg. in Arch. Scie.: Proc. of the 47th Int. Conf. of the Arch. Scie. Ass., pp. 325-333 (2013)

2. N.H. Yakubov, Account of local climatic factors in the calculation of thermal stability of enclosing structures. Bul. of the Tajik tech. Un., 1, pp. $74-77$ (2008)

3. M.V. Bodrov, A.O. Zimin, Method of calculation of thermal stability of premises of industrial agricultural buildings and constructions. SOC No. 1, pp. 102-104 (2017)

4. M.V. Bodrov, Thermal stability of premises of agricultural buildings. KazGASU, No. 1, pp. $181-185$ (2010)

5. L. Evangelist et al, Influence of the thermal inertia in the European simplified procedures for the assessment of buildings' energy performance. Sustainability, vol. 6, - №. 7, pp. 4514-4524 (2014)

6. A.G. Kochev, Study of problems of thermal stability of enclosing structures of Orthodox churches. Modern science-intensive technologies, No. 8-10, pp. 36-40 (2015)

7. O.G. Gagarina, E.V. Korkina, Assessment of thermal stability of enclosing structures and premises of buildings by frequency method. Const. and recon, No. 3 (71), pp. 4347 (2017)

8. C. Kendrick et al., Thermal mass in new build UK housing: A comparison of structural systems in a future weather scenario. En. and build., vol. 48, pp. 40-49 (2012)

9. C. Ellerbrok, Potentials of demand side management using heat pumps with building mass as a thermal storage. En. Proc., vol. 46. pp. 214-219 (2014)

10. S.A. Al-Sanea, M.F. Zedan, S.N. Al-Hussain, Effect of thermal mass on performance of insulated building walls and the concept of energy savings potential. Appl. En., vol. 89, №. 1, pp. 430-442 (2012)

11. L.S. Wang et al, A study of building envelope and thermal mass requirements for achieving thermal autonomy in an office building. En. and Build., vol. 78, pp. 79-88 (2014)

12. A.M. Shklover, Heat transfer at periodic thermal influences. Gosenergoizdat, p. 160 (1961) 
13. A.M. Shklover, Heat Stability of buildings. Gosstroizdat, Moscow, p. 166 (1952)

14. V.N. Bogoslovskiy, Building Thermophysics (thermo-physical fundamentals of heating, ventilation and air conditioning systems): Textbook for universities. $3 \mathrm{rd}$ ed. SPb.: pub. h. "AVOK NORTH-WEST", p. 400 (2006)

15. Yu.Ya. Kuvshinov, Development of the theory of thermal stability. Proc. of the II Cong. of AVOK., vol.1, pp. 35-43 (1992)

16. Yu.Ya. Kuvshinov, Energy saving systems of microclimate control in buildings. Monograph, pub. H. of the ASV, p. 320 (2010)

17. Yu.A. Tabunschikov, M.M. Brodach, Mathematical modeling and optimization of thermal efficiency of buildings. AVOK-PRESS, Moscow, p. 194 (2002)

18. E.G. Malyavina, R.R. Asatov, Influence of the thermal regime of external enclosing structures on the load of the heating system with intermittent heat supply. Acad. RAASN No. 3, pp. 324-327 (2010)

19. E.G. Malyavina, Heat stability of the room and the size of the air conditioner. Stroyprofil No. 2, pp. 60-62 (2005)

20. E.G. Malyavina, Dependence of the load on the air cooling system of the room on its thermal stability. SOC No. 12, pp. 76-77 (2015)

21. E.G. Malyavina, Joint Calculation of the Non-Stationary Thermal Mode of a Building and its Water Heating System. Materials Science Forum «Materials and Technologies in Construction and Architecture», vol. 931, pp. $905-909$ (2018) 